\section{Case Reports in Neurology}

Case Rep Neurol 2020;12:422-427

DOI: $10.1159 / 000510846$

Published online: November 12, 2020
(C) 2020 The Author(s)

Published by S. Karger AG, Basel www.karger.com/crn

This article is licensed under the Creative Commons Attribution-NonCommercial 4.0 International License (CC BY-NC) (http://www.karger.com/Services/OpenAccessLicense). Usage and distribution for commercial purposes requires written permission.

\title{
Wound Botulism Caused by Botulinum Neurotoxin Type A in a Chronic Parenteral Drug Abuser
}

\author{
Sohun Awsare David Chirikian Forshing Lui \\ California Northstate University College of Medicine, Elk Grove, CA, USA
}

\section{Keywords}

Bacterial infections - Botulinum neurotoxin type A - Neuromuscular junction disorder - Wound botulism

\begin{abstract}
Botulism is an acute paralytic disease caused by botulinum neurotoxin (BoNT)-mediated inhibition of neurosignaling at the neuromuscular junction. BoNTs are produced by gram positive, anaerobic, spore-forming bacteria from the genus Clostridium, most commonly Clostridium botulinum. Over the last decade, a previously uncommon form of botulism, wound botulism, has increased in prevalence possibly due to the rise in parenteral drug abuse. A 53-year-old patient with a history of drug abuse presents to a rural emergency department with rapidly progressing lower extremity weakness over the past few days. He reports a recent heroin injection into right buttock and diffuse skin-popping scarring was observed throughout. The patient was treated with heptavalent botulinum antitoxin obtained from the Center for Disease Control and Prevention (CDC). A right thigh abscess culture was positive for Clostridium tertium, a left hip abscess culture was positive for methicillin-susceptible Staphylococcus aureus (MSSA), and blood culture confirmed multi-microbial bacteremia caused by Staphylococcus epidermidis and Streptococcus mitis. Serum analysis was positive for BoNT type A from a suspected concurrent Clostridium botulinum infection as C. tertium is not known to produce BoNT type A. This case report highlights the importance of early antitoxin treatment for patients with suspected wound botulism.




\section{Case Reports in Neurology}

Case Rep Neurol 2020;12:422-427

\begin{tabular}{l|c|c|}
\hline DOI: $10.1159 / 000510846$ & $\odot 2020$ The Author(s). Published by S. Karger AG, Basel
\end{tabular} www.karger.com/crn

Awsare et al.: Wound Botulism Caused by Botulinum Neurotoxin Type A in a Chronic Parenteral Drug Abuser

\section{Introduction}

Botulism is an acute paralytic disease caused by the action of botulinum neurotoxins (BoNTs) on presynaptic motor neurons at the neuromuscular junction (NMJ) [1]. BoNTs are dichain proteins produced by gram positive, anaerobic, spore-forming bacteria from the genus Clostridium [1]. Clostridium botulinum produces eight serotypes of BoTNs: A, B, $\mathrm{C}_{a}, \mathrm{C}_{\mathrm{b}}, \mathrm{D}$, E, F, and G [2]. Classically, BoNT types A, B, E, and F all affect the human nervous system and may cause botulism, with types $A$ and $B$ being the most common [2-4]. Botulism presents with flaccid, symmetrically descending paralysis due to inhibited acetylcholine release and subsequent prevention of neural signaling at the NMJ [5]. Common associated symptoms include dysarthria, dysphagia, and blurred vision [6]. Clinically, botulism can manifest as six different syndromes: food-born botulism from ingestion of Clostridium spores (most common), infant botulism due to intestinal colonization of $C$. botulinum, adult intestinal botulism caused by the ingestion of spores and intestinal colonization of Clostridium species, inhaled botulism due to inhalation of Clostridium spores, iatrogenic botulism caused by highly concentrated botulinum toxin in cosmetic or therapeutic injections, and wound botulism from wound colonization of Clostridium species [7-9]. Although uncommon, wound botulism has increased in prevalence over the last decade and is often associated with parenteral drug use [9]. Here, we report a case of wound botulism caused by botulinum neurotoxin type A (BoNT type A) in a 53-yearold homeless man with a history of chronic heroin and amphetamine abuse.

\section{Case Presentation}

A 53-year-old homeless man with a history of heroin and amphetamine abuse presented to a rural emergency department with rapidly progressing lower extremity weakness over the past few days. His vital signs were normal and multiple skin-popping injection track marks were observed on the skin. No definite weakness was documented. A spinal epidural abscess was considered due to his history of parenteral drug abuse and lower extremity weakness. However, his head and thoracolumbar spine CTs were negative for any structural lesion and he was discharged from the ED after an epidural abscess was ruled out.

The patient returned to the ED the following day because of worsening weakness, shortness of breath and new onset double vision. The patient reports injecting heroin into the right buttock and was subsequently unable to rise from his sleeping bag, support his own weight, or walk. The patient was afebrile. Furthermore, he denies smoking cigarettes, marijuana, alcohol, diabetes, hypertension, peptic ulcers or asthma.

Physical examination again revealed normal vital signs. However, the patient had ptosis of the left eye, double vision on left lateral gaze, and difficulty elevating his eyebrows. A right thigh abscess and left hip abscess were defined. Bilateral thigh and gluteal skin scarring with induration were also documented. No edema was present. Splinter hemorrhages were documented under the patient's fingernails. The patient was unable to raise his head from a flexed position and compensated by pushing his chin up superiorly with his hands. Quantification of lower extremity motor strength was difficult and most probably grade 2-3/5.

The patient was then transferred to a larger hospital facility and on arrival, the patient was noted to be obtunded and unable to follow commands. There was a new progression of ocular findings including dilated and poorly reactive pupils. A non-contrast CT of the head was normal, and an MRI of the head was unremarkable except for mastoiditis. Urine toxicology was positive for opioids and amphetamine. A culture of the right thigh abscess was positive 


\section{Case Reports in Neurology}

Case Rep Neurol 2020;12:422-427

\begin{tabular}{l|l} 
DOI: 10.1159/000510846 & $\odot 2020$ The Author(s). Published by S. Karger AG, Basel \\
\hline
\end{tabular} www.karger.com/crn

Awsare et al.: Wound Botulism Caused by Botulinum Neurotoxin Type A in a Chronic Parenteral Drug Abuser

for Clostridium tertium and a culture of the left hop abscess was positive for MSSA. Additionally, the patient's serum was positive for botulinum neurotoxin type A.

The blood work conducted on this patient revealed indications of other underlying pathologies. On review, his white blood cell count $(13.3 \mathrm{~K} / \mu \mathrm{L})$ was elevated as was the platelet count $(584 \mathrm{~K} / \mu \mathrm{L})$. The mean corpuscular hemoglobin concentration $(31.7 \mathrm{~g} / \mathrm{dL})$ and the mean corpuscular volume $(24.4 \mathrm{pg})$ were low. In addition, the bicarbonate $(34 \mathrm{mmol} / \mathrm{L})$ and BUN $(19 \mathrm{mg} / \mathrm{dL}$ ) levels were elevated indicating some degree of dehydration and contraction alkalosis. Blood culture confirmed multi-microbial bacteremia caused by Staphylococcus epidermidis and Streptococcus mitis. Lumbar puncture was negative for meningitis and encephalitis. CSF cell count was normal and CSF culture was negative. Additionally, the acetylcholine receptor binding antibody, ganglioside GM1 antibody, GQ1b panel and MUSK antibody were all negative.

The management for this presentation was administration of botulinum antiserum, IV antibiotics and respiratory support. The antiserum was administered via a right femoral central venous catheter that was inserted due to poor venous access. Additionally, a 3-week course of IV antibiotics was given to cover the left hip MSSA abscess, right thigh $C$. tertium abscess, and multi-microbial bacteremia. The antitoxin was administered prior to transfer to the larger hospital facility. The respiratory complications of botulism were managed through supportive management with mechanical ventilation. The patient recovered and was discharged.

\section{Discussion/Conclusion}

Here, we described the case of a 53-year-old homeless male with a history of parenteral drug abuse who presented with rapidly progressive weakness over 2-3 days. Initially, the patient presented with lower extremity weakness followed by shortness of breath. The patient later developed progressive ocular findings, including ptosis, double-vision, and dilated, unreactive pupils. His history of parenteral drug use and lower extremity weakness raised concern for an acute spinal epidural abscess, which was ruled out by imaging. Other infectious etiologies were considered and mostly ruled out with negative neuroimaging and CSF findings. Additionally, negative antibody testing ruled out autoimmune disorders. Given his rapid progressing diffuse muscular weakness, history of parenteral drug abuse, and pupillary findings, wound botulism was considered the most probable diagnosis. This case report discusses the presentation of an uncommon form of botulism, wound botulism, and its clinical correlates.

The neuromuscular junction (NMJ) is a synapse between motor neurons and skeletal muscle fibers. NMJ signaling requires Ca2+-mediated exocytosis of acetylcholine (ACh) neurotransmitters from presynaptic motor neurons followed by ACh binding to postsynaptic skeletal muscle ACh receptors [10]. ACh vesicles stored at the axon terminus bind fusion membrane proteins including the SNARE complex in order to release ACh into the synaptic cleft [11]. Altered physiology of NMJ signal transmission confers a wide spectrum of clinical diseases and disorders. In myasthenia gravis, autoantibodies target postsynaptic ACh receptors, diminishing NMJ signaling transmission [12]. Similarly, autoantibodies targeting voltagegated presynaptic Ca2+ channels reduce NMJ signaling in Lambert-Eaton myasthenic syndrome (LEMS) [12].

All serotypes of BoNTs affect NMJ signaling transmission in the presynaptic motor neuron [13]. Structurally, BoNTs are $150 \mathrm{KDa}$ dichain proteins consisting of a light chain (LC) and heavy chain (HC) connected by a disulfide bond [14]. The LC targets high affinity receptors on 


\section{Case Reports in Neurology}

Case Rep Neurol 2020;12:422-427

DOI: $10.1159 / 000510846$

(c) 2020 The Author(s). Published by S. Karger AG, Basel www.karger.com/crn

Awsare et al.: Wound Botulism Caused by Botulinum Neurotoxin Type A in a Chronic Parenteral Drug Abuser

the presynaptic motor neuron and stimulates BoNT endocytosis [15]. While in an active state, BoNTs exhibit metalloprotease activity and cleave VAMP/synaptobrevin, SNAP-25, and synaxin proteins, thus inhibiting the formation of the SNARE complex $[16,17]$. Impairment of SNARE complex formation prevents vesicle exocytosis and ACh release into the synaptic cleft, resulting in muscular paralysis seen in botulism.

Given the patient's rapid onset of descending paralysis, a number of pathologic and infectious causes should be explored. Guillain-Barre syndrome (GBS) is an autoimmune condition that causes ascending paralysis due to antibody-mediated demyelination of peripheral neurons. The Miller-Fisher variant of GBS may cause descending paralysis and mimic the paralytic pattern of symptoms caused by botulism [18]. Similarly, Myasthenia gravis is an autoimmune presynaptic NMJ disorder that can cause muscle weakness and ocular symptoms, including ptosis and diplopia. Infectious causes, such as encephalitis and brain abscess, can both present with similar symptoms of limb weakness, respiratory distress, and fever. A stroke of the brainstem or bilateral cortex can present with ataxia and bilateral limb weakness, respectively, and were ruled out prior to treatment.

Serum testing in this patient was positive for botulinum neurotoxin type A (BoNT type A) and a right thigh abscess culture was positive for Clostridium tertium. Although not confirmed with further testing, it is suspected that a concurrent Clostridium botulinum infection also exists in this patient. Traditionally, $C$. tertium was not thought to be solely pathogenic, but new research shows that $C$. tertium has been linked to necrotizing fasciitis, gangrene, and neutropenia [19]. Importantly, C. tertium does not produce exotoxins and thus is not thought to cause botulism [19]. BoNT type A is readily produced by C. botulinum and as such, it is likely that the patient has an undetected $C$. botulinum infection in addition to $C$. tertium.

Reversal of toxicity caused by botulinum neurotoxin type A can occur based on a threepart approach that includes increasing extracellular calcium ion levels, tetanic nerve stimulation and enhancing the blockade of $\mathrm{K}+$ repolarizing currents in nerve terminals through an influx of calcium [20]. Furthermore, it has been demonstrated that there is significant synaptic plasticity that allows the nerve terminals and axons to sprout new processes and form synapses in response to the paralysis brought on by the botulinum toxicity. Changes in neuronal gene expression, de novo protein synthesis and remodeling all contribute to the improved sprouting that occurs at these nerve terminals [20].

Treatment for botulinum neurotoxicity is accomplished through a heptavalent botulinum antitoxin. The heptavalent has polyclonal antibody fragments that are able to bind free botulinum toxin. This subsequently inhibits the toxin from being endocytosed at the postsynaptic cholinergic receptor. As a result, this action decreases the amount of free neurotoxin able to block neurosignaling at the NMJ. However, heptavalent botulinum antitoxin does not work on neurotoxin that has already been internalized by the receptor [21]. The antitoxin is provided by the CDC and local health officials are alerted when reports of botulinum toxicity surface. Consequently, studies have shown that administration of the antitoxin early in disease progression has yielded the most effective outcomes [22]. Another study showed that the timeto-antitoxin administration is correlated with patient duration in the ICU and the longer the delay in administration, the longer the patient stays in the ICU [23].

In the most recent $\mathrm{CDC}$ survey regarding wound botulism toxicity, there were 182 instances of laboratory diagnosed toxicity. Of these 182 cases, 19 (10\%) were related to wound botulism toxicity and 17 (89\%) of these instances were related to drug injection. There were 18 instances (94\%) of toxin type A being detected in the patient as the underlying cause for the toxicity. A majority of these cases occurred in California (84\%) with one case each showing up in New Mexico, Arizona and Washington. Fifteen (78\%) of the cases appeared in men [24]. 


\section{Case Reports in Neurology}

\begin{tabular}{l|l}
\hline Case Rep Neurol 2020;12:422-427 \\
\hline DOI: 10.1159/000510846 & $\begin{array}{l}\text { @ 2020 The Author(s). Published by S. Karger AG, Basel } \\
\text { www.karger.com/crn }\end{array}$ \\
\hline
\end{tabular}

Awsare et al:: Wound Botulism Caused by Botulinum Neurotoxin Type A in a Chronic Parenteral Drug Abuser

Additionally, this patient is a black tar heroin drug user and numerous studies have explored the link between wound botulism and the use of black tar heroin $[25,26]$. One study reviewed case data from 1993 to 2006 and found 17 IV drug users that had wound botulism. Of them, 15 of the participants indicated black tar heroin use. These patients presented most commonly with a visible wound (88\%), speech difficulty (82\%) and double vision (64\%) [25]. In another study reviewing the use of heroin with wound botulism, the authors found 35 cases over a 26-month period. Of the ones that were classified, they found 30/34 (88\%) were associated with botulinum neurotoxin type $A$ and the remaining were associated with botulinum neurotoxin type B. They also found that 33 (94\%) of the 35 patients injected black tar heroin either subcutaneously or intramuscularly [26]. The patient reviewed in this case report also injected heroin parenterally as he reported that he was unable to find good veins for injection.

In summary, consider wound botulism in any patient with a history of parenteral drug abuse presenting with acute onset or rapidly progressive weakness or paralysis. Additional ocular findings and respiratory distress should also be indicators for neuromuscular junction dysfunction. Early antitoxin therapy is a specific treatment which may speed up recovery and reduce morbidity in patients with wound botulism.

\section{Acknowledgement}

We thank all members of our research team for their assistance with this project. Particularly, we would like to thank Dr. Rodgers for providing support and guidance as we worked through this project.

\section{Statement of Ethics}

The patient described in this paper (or his guardians) has given written, informed consent to publish his case, radiographic images, and pathological reports. The research in this paper was conducted ethically in accordance with the World Medical Association Declaration of Helsinki.

\section{Conflict of Interest Statement}

The authors have no conflicts of interest to declare.

\section{Funding Sources}

No funding sources to be reported.

\section{Author Contributions}

Sohun Awsare and David Chirikian equally contributed to reviewing the patient chart, conducting a literature review and drafting the manuscript. Dr. Forshing Lui reviewed literature and revised the manuscript. 


\section{Case Reports in Neurology}

\section{References}

1 Huang W, Foster JA, Rogachefsky AS. Pharmacology of botulinum toxin. J Am Acad Dermatol. 2000 Aug;43(2 Pt 1):249-59.

2 Smith LD, Sugiyama H. Botulism: the organism, its toxins, the disease. 2nd ed. Springfield (IL): Charles C Thomas; 1988.

3 Rossetto 0, Pirazzini M, Montecucco C. Botulinum neurotoxins: genetic, structural and mechanistic insights. Nat Rev Microbiol. 2014 Aug;12(8):535-49.

4 Eleopra R, Tugnoli V, Quatrale R, Rossetto O, Montecucco C. Different types of botulinum toxin in humans. Mov Disord. 2004 Mar;19(S8 Suppl 8):S53-9.

5 Pirazzini M, Rossetto 0, Eleopra R, Montecucco C. Botulinum Neurotoxins: Biology, Pharmacology, and Toxicology. Pharmacol Rev. 2017 Apr;69(2):200-35.

6 Shapiro RL, Hatheway C, Swerdlow DL. Botulism in the United States: a clinical and epidemiologic review. Ann Intern Med. 1998 Aug;129(3):221-8.

7 Sobel J. Botulism. Clin Infect Dis. 2005;41(8):1167-73.

8 Chertow DS, Tan ET, Maslanka SE, Schulte J, Bresnitz EA, Weisman RS, et al. Botulism in 4 adults following cosmetic injections with an unlicensed, highly concentrated botulinum preparation. JAMA. 2006 Nov;296(20):2476-9.

9 Schulte M, Hamsen U, Schildhauer TA, Ramczykowski T. Effective and rapid treatment of wound botulism, a case report. BMC Surg. 2017;17(1):103. Published 2017 Oct 26. doi: https://doi.org/10.1186/s12893-0170300-4.

10 Dorner MB, Schulz KM, Kull S, Dorner BG. Complexity of botulinum neurotoxins: challenges for detection technology. Curr Top Microbiol Immunol. 2013;364:219-55.

11 Südhof TC, Rizo J. Synaptic vesicle exocytosis. Cold Spring Harb Perspect Biol. 2011;3(12):a005637. Published 2011 Dec 1. doi: https://doi.org/10.1101/cshperspect.a005637.

12 Verschuuren J, Strijbos E, Vincent A. Neuromuscular junction disorders. Handb Clin Neurol. 2016;133:44766.

13 Dressler D, Adib Saberi F. Botulinum toxin: mechanisms of action. Eur Neurol. 2005;53(1):3-9.

14 Pellett S, Bradshaw M, Tepp WH, Pier CL, Whitemarsh RC, Chen C et al. The Light Chain Defines the Duration of Action of Botulinum Toxin Serotype A Subtypes. mBio. 2018;9(2):e00089-18. Published 2018 Mar 27. doi:https://doi.org/10.1128/mBio.00089-18.

15 Rummel A. Double receptor anchorage of botulinum neurotoxins accounts for their exquisite neurospecificity. Curr Top Microbiol Immunol. 2013;364:61-90.

16 Schiavo G, Poulain B, Rossetto O, Benfenati F, Tauc L, Montecucco C. Tetanus toxin is a zinc protein and its inhibition of neurotransmitter release and protease activity depend on zinc. EMBO J. 1992b Oct;11(10):3577-83.

17 Schiavo G, Rossetto O, Catsicas S, Polverino de Laureto P, DasGupta BR, Benfenati F, et al. Identification of the nerve terminal targets of botulinum neurotoxin serotypes A, D, and E. J Biol Chem. 1993a Nov;268(32):23784-7.

18 Dimachkie MM, Barohn RJ. Guillain-Barré syndrome and variants. Neurol Clin. 2013 May;31(2):491-510.

19 Ray P, Das A, Singh K, Bhansali A, Yadav TD. Clostridium tertium in necrotizing fasciitis and gangrene. Emerg Infect Dis. 2003 Oct;9(10):1347-8.

20 Meunier F, Schiavo G, Molgo J. Botulinum neurotoxins: from paralysis to recovery of functional neuromuscular transmission. Journal of Physiology, Paris. 2002 Jan-March; 96(1-2):105-13. doi: https://doi.org/10.1016/S0928-4257(01)00086-9.

21 Schussler E, Sobel J, Hsu J, Yu P, Meaney-Delman D, Grammer LC, et al. Workgroup Report by the Joint Task Force Involving American Academy of Allergy, Asthma \& Immunology (AAAAI); Food Allergy, Anaphylaxis, Dermatology and Drug Allergy (FADDA) (Adverse Reactions to Foods Committee and Adverse Reactions to Drugs, Biologicals, and Latex Committee); and the Centers for Disease Control and Prevention Botulism Clinical Treatment Guidelines Workgroup-Allergic Reactions to Botulinum Antitoxin: A Systematic Review. Clin Infect Dis. 2017 Dec;66(suppl_1):S65-S72.

22 Chang GY, Ganguly G. Early antitoxin treatment in wound botulism results in better outcome. Eur Neurol. 2003;49(3):151-3

23 Offerman SR, Schaefer M, Thundiyil JG, Cook MD, Holmes JF. Wound botulism in injection drug users: time to antitoxin correlates with intensive care unit length of stay. West J Emerg Med. 2009 Nov;10(4):251-6.

24 Centers for Disease Control and Prevention (CDC). Botulism Annual Summary, 2017. Atlanta, Georgia: U.S. Department of Health and Human Services, CDC; 2019.

25 Yuan J, Inami G, Mohle-Boetani J, Vugia DJ. Recurrent wound botulism among injection drug users in California. Clin Infect Dis. 2011 Apr;52(7):862-6.

26 Passaro DJ, Werner SB, McGee J, Mac Kenzie WR, Vugia DJ. Wound botulism associated with black tar heroin among injecting drug users. JAMA. 1998 Mar;279(11):859-63. 